\title{
MET OFFICE UNIFIED MODEL HIGH RESOLUTION SIMULATIONS OF A STRONG WIND EVENT IN ANTARCTICA
}

Andrew Orr ${ }^{1}$, Tony Phillips ${ }^{1}$, Stuart Webster ${ }^{2}$, Andy Elvidge ${ }^{3}$, Mark Weeks ${ }^{2}$, J. Scott Hosking ${ }^{1}$ and John Turner ${ }^{1}$

1. British Antarctic Survey, Cambridge, United Kingdom

2. Met Office, Exeter, United Kingdom

3. University of East Anglia, Norwich, United Kingdom

Corresponding author current affiliation and address:

Dr Andrew Orr, British Antarctic Survey, High Cross, Madingley Road, Cambridge, CB3 0ET

Tel: +44 (0)1223 221 256; e-mail: anmcr@bas.ac.uk

Submitted to: Quarterly Journal of the Royal Meteorological Society

May 2013

This article has been accepted for publication and undergone full peer review but has not been through the copyediting, typesetting, pagination and proofreading process, which may lead to differences between this version and the Version of Record. Please cite this article as doi: 10.1002/qj.2296 


\begin{abstract}
During winter much of the Antarctic coast is susceptible to severe and hazardous strong wind events (SWEs) associated with the enhancement of katabatic winds by synoptic weather systems. In this study a SWE which occurred at Mawson, East Antarctica involving a hurricane force wind speed of $\sim 39 \mathrm{~m} \mathrm{~s}^{-1}$ is simulated by the Met Office Unified Model at high horizontal resolutions with grid lengths between 12 and $1.5 \mathrm{~km}$. It is shown that all the simulations capture the qualitative evolution of the SWE but underestimate its peak wind speed. The extent of the underestimate is dependent on horizontal resolution, with the 4 and $1.5-\mathrm{km}(12-\mathrm{km})$ models under-forecasting the peak wind speed by around $15 \%(36 \%)$. In addition to a strengthening of the katabatic flow, the simulated low-level cyclonic winds associated with the depression responsible for the SWE caused the formation of a barrier-type jet parallel to the coast, resulting in strong wind convergence/interaction at the coastline and suggesting a strong topographic influence on the dynamics responsible for SWE formation. Moreover, that Mawson is influenced by small-scale gravity waves which formed in response to the stronger winds, and that representation of this was particularly sensitive to horizontal resolution. Additional experiments suggest that the Met Office Unified Model simulation of the SWE is most sensitive to the representation of turbulent mixing under stable conditions. This study is important to identify shortcomings in the performance of the Met Office Unified Model near Antarctica's coastal regions as well as to improve understanding of the processes responsible for SWEs.
\end{abstract}

Keywords: Met Office Unified Model; high resolution modeling; Antarctica; strong wind event; dynamics; orographic effects 


\section{Introduction}

For a number of reasons the Antarctic coastline experiences some of the most intense and sustained near-surface winds on Earth. Firstly, the persistence of strong and directionally constant katabatic winds is a characteristic feature of the Antarctic winter climate. Such winds form due to strong and sustained radiational cooling of the surface air on the interior plateau of the Antarctic ice sheet. This cold air is negatively buoyant and flows under the influence of gravity from the high interior down to the coasts, with the strongest katabatic winds being found in the coastal regions in response to the steeper slopes, and particularly down valleys where the winds are funnelled (e.g., Parish and Bromwich, 1987; Parish 1988). The Coriolis force has a significant influence on the katabatic winds, deflecting them to the left of the topographic fall line in the Southern Hemisphere, and causing them to have a strong westwards component near the coast. Secondly, the many synoptic-scale depressions which travel just off the Antarctic coastal region (e.g., Simmonds and Keay, 2000) produce strong winds due to their tight pressure gradients, which in conjunction with the steep terrain at the continent's edge are typically confined to the coastal margins. Some of the most extreme strong wind events (SWEs) occur when these two processes interact, i.e. when the synoptic pressure gradient force acts along with the downslope-directed katabatic pressure gradient force (e.g., Parish and Bromwich, 1998; van den Broeke and van Lipzig, 2003;Turner et al., 2009). Turner et al. (2009) showed using in-situ observations collected over the last 60 years that this mechanism was responsible for the majority of SWEs around the coast of East Antarctica during its extended winter season, i.e. by showing that SWEs were almost exclusively accompanied by large negative mean sea level pressure anomalies, suggesting the presence of a low pressure system in the vicinity. The approach of a 
depression and its associated relatively mild maritime air mass means that SWEs are also associated with positive temperature anomalies (Turner et al., 2009).

Near-surface atmospheric flow at Antarctica's coastline can be considered complex for other reasons, particularly in winter when the extremely cold temperatures over both land and extensive sea-ice result in highly stable conditions. For example, the presence of sea-ice produces strong gradients in surface roughness and temperature (e.g., King and Turner, 1997; Weiss et al., 2011). The resulting sharp changes in the turbulent fluxes of momentum and heat have a significant influence on the near-surface wind speed and temperature, e.g., the generation of localised coastal wind jets (Hunt et al., 2004; Orr et al., 2005a; Owinoh et al., 2005). Orographic gravity waves can be excited by stably stratified flow (such as katabatic winds) moving over the steep, local features which characterise the coastline of Antarctica, such as small hills and mountains, cliffs, and outcrops (e.g., Watanabe et al., 2006; Valkonen et al., 2010), resulting in surface fluctuations of wind, temperature, and pressure (Rees et al., 2000). Wind speed and direction at the near-surface are also influenced directly by the shape and size of local topography. Furthermore, when depressions are present the low-level cyclonic winds are sometimes unable to ascend the steep slopes if the air is cold and stable (i.e. low-level flow blocking), resulting in much of the flow being forced parallel to the coastline and the formation of what is known as a barrier jet (e.g., O'Connor et al., 1994; Orr et al., 2004, 2005b; Nigro et al., 2012). A detached jet forms when there is a sharp change in the orientation of the coastline (e.g., at a promontory, cape, or bay), in response to the flow both continuing downstream in the same direction as the barrier jet and strengthening (Hunt et al., 2004; Orr et al., 2005a, 2005b). 
Turner et al. (2009) showed that the simulated recorded wind speed of SWEs was severely underestimated by a regional atmosphere-only version of the Met Office Unified Model (hereafter referred to as MetUM) with a horizontal resolution of $12 \mathrm{~km}$. This suggests that a finer resolution is required to improve the representation of the dynamical and physical processes (both explicitly and through improved realisation of complex surface features) and/or some of the key physical processes of the Antarctic troposphere are not well represented in the model. This is consistent with the study of Bromwich et al. (2005) which showed using the Antarctic Mesoscale Prediction System (AMPS) that increasing the resolution from $10 \mathrm{~km}$ to $3.3 \mathrm{~km}$ improved the simulation of surface wind over the complex terrain surrounding McMurdo, West Antarctica, and also with the known difficulty of the model representation of surface and boundary-layer turbulent fluxes under highly stable conditions, which require parameterization (e.g., King et al., 2001; Tastula and Vihma, 2011). However, of note is the study of Powers (2007) which suggested that even at resolutions of a few kilometres that the Weather Research and Forecasting (WRF) model underestimates the peak wind speed of significant Antarctic events. (A similar result was shown by Webster et al. (2008) for a severe weather event over New Zealand.) Furthermore, Bromwich et al. (2003) showed that the performance of AMPS at $10 \mathrm{~km}$ resolution was sensitive to the quality of the data used for initial conditions (which at high southern latitudes are often questionable (Bracegirdle and Marshall, 2012) due to the limited in-situ observations). Note that other modelling studies devoted to SWEs used much coarser horizontal resolutions of between 30 and $90 \mathrm{~km}$ (e.g., Turner et al., 2001; Parish and Cassano, 2003; Adams, 2005).

One station which has an exposed location on the coast and where the ice sheet rises steeply inland is the Australian base of Mawson, which sits on an isolated and rocky area of the East 
Antarctica coast at $67.6{ }^{\circ} \mathrm{S}, 62.9^{\circ} \mathrm{E}$ (see Fig. 1 for location). About $\sim 10 \mathrm{~km}$ inland of Mawson are the Framnes Mountains, which is a chain of nunataks running in a east-west direction and which extend 300 to $400 \mathrm{~m}$ above the surrounding ice sheet (Streten, 1990). Mawson is characterised by winds exceeding gale force $\left(>17.2 \mathrm{~m} \mathrm{~s}^{-1}\right)$ at least $16 \%$ of the time and a mean annual wind speed of $11.2 \mathrm{~m} \mathrm{~s}^{-1}$ (Turner et al., 2009). A comprehensive climatology of Mawson, which stresses the importance of synoptic disturbances in producing extreme, prolonged gale periods, is provided by Streten (1990). Streten (1968) suggests that the wind regime at Mawson is typical of other strong wind sites on the coastal sector of East Antarctica, such as the other two Australian bases of Casey and Davis.

The ability of weather forecasters to predict such strong and rapidly changing surface winds is important for planning logistical and scientific operations at Antarctic stations, which are predominately based at coastal locations and heavily reliant on the use of flights. As well as aircraft not being able to land or take off during high wind speeds, strong winds can also greatly reduce visibility by blowing snow. Such forecasts are principally based on numerical weather prediction (NWP) guidance. Forecasts at Mawson, Casey and Davis currently rely on the global MetUM forecasts at N320 (domain size of $640 \times 481$ grid points, or $0.5625^{\circ} \times$ $\left.0.375^{\circ}\right)$ horizontal resolution.

In this paper the ability of the MetUM to capture SWEs is assessed by running regional highresolution simulations of a case which involved a hurricane force wind speed of $\sim 39 \mathrm{~m} \mathrm{~s}^{-1}$ that occurred at Mawson early on 25 July 2004 (Turner et al., 2009). In addition to operational forecasting, assessing the MetUM performance is important for research purposes by identifying deficiencies in the model and aspects of it which will require improvements in the future. Model development, understanding and application of the MetUM has primarily 
been at mid-latitudes, with it being used to model the extreme conditions of the polar regions on only a few occasions, and never at grid lengths finer than $12 \mathrm{~km}$ (e.g., Orr et al., 2004, 2005b, 2008; Petersen et al., 2009; Turner et al., 2009). Indeed, to meet the requirements unique to the polar regions, some systems such as the WRF model employ 'polar' versions (Bromwich et al., 2009).

Our main objective is to examine the impact of increasing horizontal resolution on the results by running simulations at grid lengths of 12,4 and $1.5 \mathrm{~km}$. However, by examining the evolution of model fields on regional and local scales and their sensitivity to horizontal resolution, we also hope to gain further insight into the forcing mechanisms and meteorological understanding of SWEs. Section 2 presents a description of the MetUM and the model runs. Section 3 presents a comparison of the model output with station data at Mawson and the sensitivity of model fields to horizontal resolution. To help distinguish between the effect on the results of finer resolution and the representation of key physical processes, section 3 also discusses the results of various experiments examining the sensitivity to the model configuration/setup including dynamics and physics choices. Section 4 presents a discussion. The study finishes with a summary, which is presented in section 5 .

\section{Model and methodology}

The MetUM configuration used in this study is based on version 7.6, and is similar to that described in Davies et al. (2005) and Webster et al. (2008). To compare the impact of increasing horizontal resolution on the representation of the SWE case study, the 'base' 12, 4, and $1.5-\mathrm{km}$ models used the same dynamics and physics choices. Note that the three models 
each use 70 vertical levels, starting at $5 \mathrm{~m}$ above the surface and reaching a height of $40 \mathrm{~km}$ (with 11 of the 40 levels located in the lowest $500 \mathrm{~m}$ of the atmosphere).

\subsection{Dynamics and physics}

The MetUM is a NWP system used for both research and operational forecasting purposes. It can be run as a mesoscale, atmosphere-only model with a horizontal grid resolution as high as 100 meters. It is a grid-point model and uses non-hydrostatic dynamics with semi-lagrangian advection and semi-implicit time stepping. When run as a mesoscale model the multi-level primitive equations are solved on a rotated latitude-longitude grid (to achieve uniform resolution) with Arakawa $\mathrm{C}$ staggering and a hybrid-height vertical coordinate (i.e. terrain following near the surface) with Charney-Philips staggering. Here, the models use the options of: i) a fully three-dimensional potential temperature advection scheme (in conjunction with a $15 \mathrm{~s}$ time step, required in order to run stably at high resolution) and ii) significantly reduced temporal off-centering in the advection scheme (which decreases as the time step decreases). The practical result of this is that gravity waves are more accurately resolved. These modifications were used by Webster et al. (2008) to successfully simulate at high-resolution a severe weather event in New Zealand using the MetUM. Note that for consistency the 12,4 , and $1.5-\mathrm{km}$ models all use a $15 \mathrm{~s}$ time step, although such a short time step is not normally used for comparatively lower-resolution models, e.g. Webster et al. (2008) ran the MetUM at $12 \mathrm{~km}$ horizontal resolution with a time step of $300 \mathrm{~s}$.

The MetUM includes a detailed set of physics packages, including those for the boundary layer, surface, radiation, cloud, and sub-grid scale orography. For stable conditions, the boundary-layer scheme is described by Brown et al. (2008) and uses an eddy diffusivity 
approach to relate the turbulent fluxes to the local mean conditions. The eddy diffusivities are proportional to a mixing length, the vertical wind shear, and the local stability via a Richardson number $(R i)$ dependent stability function. The models use the 'sharp' stability function, which decays rapidly with increasing stability (in proportion to $1 / R i^{2}$ ), resulting in relatively weak turbulent mixing at high stability. The mixing length is a function of the surface roughness length, which for snow over land (i.e. the Antarctic ice sheet) is specified as $5 \times 10^{-4} \mathrm{~m}$. The roughness length of sea-ice is also specified as $5 \times 10^{-4} \mathrm{~m}$, which is in agreement with observations for winter Antarctic pack ice made by Wamser and Martinson (1993). The roughness length over the sea is dependent on the wind speed and is obtained using the Charnock formula (Smith 1988), with a Charnock constant $\beta=0.011$. A Smagorinsky-type scheme enabling sub-grid turbulent mixing in the horizontal both in the boundary layer and throughout the free troposphere is implemented. The practical result of this is the damping of unphysical grid-scale structures which can cause stability problems. The sub-grid orographic drag resulting from the effects of flow blocking and gravity waves due to mesoscale orographic features not resolved by the model (i.e. small mountain ranges) is described by Webster et al. (2003). However this scheme was switched off as sensitivity tests showed that for the simulations discussed here its impact was negligible (not shown). Additional sub-grid orographic drag resulting from the effects of flow over local orographic features not resolved by the models (i.e. individual hills) is described by Wood and Mason (1993) and is represented by an effective ('orographic') roughness length, which is proportional to a drag coefficient $C_{\mathrm{D}}$. This parameterization is very efficient at slowing lowlevel winds, so a value of $C_{\mathrm{D}}=0.01$ is chosen so as to achieve realistically strong wind speeds at the surface (i.e. effectively this scheme has been turned off). 


\subsection{Model domains and orography}

The model domains are shown in Fig. 1 and are made up of: i) a 12-km grid covering the entire Antarctic continent (domain size of $700 \times 542$ grid points), and ii) 4 and $1.5-\mathrm{km}$ grids covering a significant but progressively smaller region of East Antarctica which encompasses Mawson (domain sizes of $750 \times 750$ and $1300 \times 1000$ grid points, respectively). The model orography is interpolated from version 9 of the Radarsat Antarctic Mapping Project (RAMP) Digital Elevation Model (DEM) of Antarctica at $200 \mathrm{~m}$ resolution (Liu et al., 2001; incorporating topographic data from satellite radar altimetry and airborne radar surveys), using bilinear interpolation and a 1-2-1 smoother.

Figure 1 also illustrates the general steepening of the Antarctic orography near the coastal margins. To better understand the sensitivity of the model representation of orography at Mawson, Fig. 2 compares the height of the three model grids with that of the DEM and ECMWF Interim Reanalysis (Dee et al., 2011; referred to as ERA Interim and has a N128 (nominally $0.70^{\circ}$ ) horizontal resolution) along transects oriented in both the south-to-north and west-to-east directions. The north-to-south transect shows the DEM rising by $\sim 1000 \mathrm{~m}$ within $40 \mathrm{~km}$ inland of the coastline. This slope is well captured by the models, and in particular the $1.5-\mathrm{km}$ grid. Although as the horizontal resolution decreases it is evident (as expected) that the slope is progressively smoothed/flattened, so that the height at Mawson (interpolated from the surrounding grid points) systematically increases with decreasing resolution (to the extent that its elevation at Mawson in ERA Interim is greater than $450 \mathrm{~m}$, in contrast to its actual elevation of around $16 \mathrm{~m}$ ). Consequently, ERA Interim (and to a lesser extent the 12 and 4-km grids) shows land extending erroneously many kilometres out over the sea. Bromwich et al. (2005) suggests that this can cause systematic biases in model near- 
surface winds at coastal stations due to the stations being erroneously located further from the ocean (where the winds are often stronger) in the model. The west-to-east oriented transect shows slightly steeper slopes (1:33 immediately west of Mawson) which are well captured by the 4 and $1.5-\mathrm{km}$ grids, slightly flattened by the $12-\mathrm{km}$ grid, and completely misrepresented by ERA Interim.

\subsection{Initial and lateral boundary conditions}

The three model simulations were run sequentially, i.e. the $12-\mathrm{km}(4-\mathrm{km})$ model provides initial and lateral boundary conditions for the $4-\mathrm{km}(1.5-\mathrm{km})$ model. Before this can take place a (version 7.1) 'standard' global MetUM simulation at N320 resolution (i.e., including a sub-grid orographic drag scheme, etc) is run to provide the start data and lateral boundary conditions for the $12-\mathrm{km}$ model. This is initialised at 0000 UTC 24 July 2004 using ERA Interim fields and run forward for $+48 \mathrm{~h}$, with the first $1 \mathrm{~h}$ discarded for spinup reasons. Note that ERA Interim was determined to give the most reliable representation of the largescale Antarctic circulation in a recent study by Bracegirdle and Marshall (2012). Subsequently, the $12-\mathrm{km}$ model is initialised at 0100 UTC 24 July using start data provided by the global model integration and run forward for $+47 \mathrm{~h}$ using lateral boundary conditions at hourly intervals also provided by the global model integration. The $12-\mathrm{km}$ model is additionally initialised at 0100 UTC 24 July by daily: i) Bootstrap sea-ice fraction data at a resolution of $25 \mathrm{~km}$ (Comiso, 1999) and, ii) GHRSST sea surface temperature data (Reynolds et al., 2007) at a resolution of 0.25 degrees. This is used to represent as realistically as possible the extensive distribution of sea ice which surrounds Mawson during the case study (Fig. 1 also indicates the sea-ice edge on 0000 UTC 25 July, showing the ice edge extending north from the Antarctic coastline for many hundreds of kilometres). Following this, the 4- 
$\mathrm{km}(1.5-\mathrm{km})$ model is initialised at 0200 UTC 24 July (0300 UTC 24 July) and run forward for $+46 \mathrm{~h}(+45 \mathrm{~h})$ using start data and lateral boundary conditions at $30 \mathrm{~min}$ intervals provided by the $12-\mathrm{km}(4-\mathrm{km})$ integration.

\subsection{Validation methodology}

The performance of the MetUM is evaluated by comparing model output at 12,4 , and $1.5-\mathrm{km}$ resolution with observed near-surface meteorological variables recorded 3-hourly at Mawson. The variables used in the verification are near-surface $(10 \mathrm{~m})$ wind speed and direction, nearsurface $(2 \mathrm{~m})$ temperature, and sea level pressure (derived from surface pressure). To this end, all models provide output every 3 hours from 0600 UTC 24 July to 0000 UTC 26 July. For simplicity, we reference the forecast/simulation time of all models relative to 0000 UTC 24 July. The observed values are obtained by averaging over a 10 minute interval while the MetUM output are based on instantaneous values. Separate sensitivity tests showed that the MetUM instantaneous output was representative of its 10 minute averaged output (not shown). The representation of the event in ERA Interim is also examined, principally to provide an overview/understanding of the synoptic evolution.

\section{Results}

\subsection{Evolution of the SWE from observations and reanalysis}

Figure 3 shows the Mawson station data for 24-25 July 2004. Evident is a sharp peak in surface winds, with speeds strengthening over a $24 \mathrm{~h}$ period from $\sim 0 \mathrm{~m} \mathrm{~s}^{-1}$ to a maximum of $\sim 39 \mathrm{~m} \mathrm{~s}^{-1}$ at around 0000 UTC 25 July, followed by weakening back to speeds of a few m s${ }^{-1}$ 
over the subsequent $24 \mathrm{~h}$ period. The period of strengthening winds is coincident with the sea level pressure falling by over $40 \mathrm{hPa}$, suggesting that the wind is strengthening in response to the approach of a depression, although the pressure minimum $(\sim 944 \mathrm{hPa})$ occurs around 3 to $6 \mathrm{~h}$ after the wind speed maximum. Similarly, the period of weakening wind speed is largely coincident with rising pressure, i.e. the departure of a depression. Also occurring over this time is a steady rise of around $10{ }^{\circ} \mathrm{C}$ in near-surface temperature between 0000 UTC 24 July and roughly 1200 UTC 25 July, and a gradual veering of the wind from an easterly $\left(\sim 100^{\circ} \mathrm{E}\right)$ direction at around 0600 UTC 24 July to a more south-easterly direction $\left(\sim 120^{\circ} \mathrm{E}\right)$ at around 1200 UTC 25 July.

The passing of a large depression close to Mawson is clearly illustrated by ERA Interim sea level pressure fields shown in Fig. 4(a-c) at 1200 UTC 24 July, 0000 UTC 25 July, and 1800 UTC 25 July, which are respectively representative of the onset, strongest phase, and cessation of the SWE. Note that: i) the domain size of the panels in Fig. 4 is $1800 \times 1800 \mathrm{~km}$ so as to capture the movement of the depression from west to east during these three times, and ii) the sea level pressure field is masked over the land (as here it has little meaning due to it reflecting the effect of the high terrain rather than the synoptic weather patterns). As such, these panels are primarily suited to investigation of the evolution of large scale circulation features. ERA Interim shows a deep low with tightly bunched isobars and a central pressure of $956 \mathrm{hPa}$ positioned west and north of Mawson at 1200 UTC 24 July. By 0000 UTC 25 July the central pressure has deepened considerably to $940 \mathrm{hPa}$ (and the isobars have bunched tighter) and the system has moved eastward and southward, so that it is positioned just north of Mawson. By 1800 UTC 25 July the central pressure has weakened to $960 \mathrm{hPa}$ and the system has moved past (east of) Mawson, with the isobars become much more widely spread. This movement is broadly supported by infrared satellite imagery (not shown), which show 
an associated frontal cloud band consistent with these positions. The satellite imagery shows the cloud band becoming more tightly wrapped around the centre of the low at 0000 UTC 25 July, suggesting that the deepening of the depression at this time is realistic. By 1800 UTC 25 July the spiral cloud bands have broken up, consistent with the system weakening.

The ERA Interim $10 \mathrm{~m}$ wind field is also included in Fig. 4. At 1200 UTC 24 July this shows: i) the synoptic winds over the ocean impinging on the stretch of coastline which includes Mawson and decelerating, resulting in a reduced Coriolis force and a rightward deflection of the flow, ii) the formation of a barrier jet along the coastline, iii) a band of easterly katabatic winds near the coast, and iv) accelerating flow exiting the valley to the east of Mawson, resulting in a increased Coriolis force and a leftward deflection. The combination of these various forcing mechanisms is a strong convergence of the wind field at the coastline, and the formation of a relatively narrow westward barrier-type jet with speeds of $10-15 \mathrm{~m} \mathrm{~s}^{-1}$. By 0000 UTC 25 July the katabatic winds and the synoptically driven flow impinging on the coastline have both strengthened considerably (culminating in speeds in excess of $20 \mathrm{~m} \mathrm{~s}^{-1}$ ), resulting consequently in stronger convergence at the coastline and strengthening of the barrier-type jet (reaching speeds in excess of $25 \mathrm{~m} \mathrm{~s}^{-1}$ ). However, the winds across the coastline have an obvious south-easterly signature characteristic of katabatic winds. At 1800 UTC 25 July a marked weakening of the winds occurs over both the land and the ocean, and consequently significantly reduced convergence at the coastline.

Figure 3 allows a comparison between the observations at Mawson and ERA Interim data (interpolated to Mawson's location). ERA Interim captures the timing of the SWE in terms of both its minimum in sea level pressure and its maximum in $10 \mathrm{~m}$ wind speed. However, it underestimates the peak wind speed by around 36\% (maximum wind speed of $\sim 25 \mathrm{~m} \mathrm{~s}^{-1}$ ) and 
the minimum sea level pressure by $\sim 10 \mathrm{hPa}$. Although ERA Interim represents the observed steadily increasing temperatures, it has a relatively large cold bias of $\sim 5{ }^{\circ} \mathrm{C}$ (also consistent with erroneously high orography). For the duration of much of the case study ERA Interim showed a good representation of the wind direction.

\subsection{Representation of the SWE in simulations}

\section{a. Sensitivity to horizontal resolution}

Figure 3 further allows a comparison between the station observations and the model output (interpolated to Mawson's location). It is apparent that all the models: i) capture the qualitative evolution of the SWE, ii) capture the weaker wind speeds associated with the onset of the SWE, and iii) underestimate the peak wind speed. The strength of the underestimate is dependent on horizontal resolution, with the 4 and $1.5-\mathrm{km}(12-\mathrm{km})$ models under-forecasting the peak wind speed by around $15 \%(36 \%)$. On close inspection it is also apparent that: i) although the evolution of the 4 and $1.5-\mathrm{km}$ model wind speeds are similar, they actually only converge/agree from around $\sim 24 \mathrm{~h}$ into the simulation (at their representation of the peak wind speed), with prior to this the stronger winds simulated by the 1.5-km model in better agreement with the observations, ii) the evolution of the 12 and $4-\mathrm{km}$ model wind speeds starts to diverge from $\sim 12 \mathrm{~h}$ into the simulations (when the wind speed is $10-15 \mathrm{~m} \mathrm{~s}^{-1}$ ), iii) the $1.5-\mathrm{km}$ model representation of the strengthening wind starts to diverge from the observations from 12-18 $\mathrm{h}$ into the simulations (when the wind speed reaches

approximately $20 \mathrm{~m} \mathrm{~s}^{-1}$ ), and iv) during the cessation of the SWE (which the 12 and 4-km models simulate overly early) the winds simulated by the $1.5-\mathrm{km}$ model are in good agreement with the observations (although overly strong towards the end of the simulation). 
Figure 3 shows that all models are able to capture the timing of the minimum in sea level pressure and the steady reduction preceding it. However, all models show: i) a minimum pressure which is higher than observed (by $\sim 2 \mathrm{hPa}$ for both the 4 and 1.5-km models and $\sim 5$ $\mathrm{hPa}$ for the 12-km model), and ii) an underestimate of the rise in pressure which follows. Note that unlike the wind speed, the sea level pressure simulated by the 4 and $1.5-\mathrm{km}$ models does not diverge from the observations as the wind strengthens. For the duration of much of the case study all the models show a good representation of the wind direction. From around 1200 UTC 25 July they misrepresent the significant veer of the wind. All models capture the timing of the peak temperature and the steady warming preceding it, but broadly underestimate the actual temperature by $\sim 2^{\circ} \mathrm{C}$ (although not at the time of the peak winds). It is notable that the evolution of the 4 and $1.5-\mathrm{km}$ model temperature appears remarkably similar.

Figure 4 shows model output as well as the ERA Interim data. Immediately apparent is the marked agreement in sea level pressure between the models. At 1200 UTC 24 July all three models show a low with location consistent with ERA Interim but with a central pressure which is $\sim 8 \mathrm{hPa}$ lower $(948 \mathrm{hPa}$ ). (Note that Bracegirdle (2012) showed, in a comparison with mean sea-level pressure data from ice drifting buoys in the Bellingshausen Sea (situated along the west side of the Antarctic Peninsula), that although ERA Interim was clearly the most accurate reanalyses at representing individual weather systems, it was nevertheless characterised by a small positive bias in pressure.) Consequently, the packing of contours eastward of the low's center is tighter in the model results. At 0000 UTC 25 July all three models again show the location of the low consistent with ERA Interim but a central pressure which is $\sim 4 \mathrm{hPa}$ lower $(936 \mathrm{hPa})$. At $1800 \mathrm{UTC} 25 \mathrm{July}$ the position of the low in all three 
models is eastward of its location in ERA Interim, showing it is sitting a little north of the Amery Ice Shelf. All three models show a lower central minimum pressure than in ERA Interim, with both the 12 and 4-km models showing a value of $952 \mathrm{hPa}$ and the $1.5-\mathrm{km}$ model a value of $948 \mathrm{hPa}$.

Not surprisingly given the close agreement between the model sea level pressure fields, Fig. 4 shows that the evolution of the large-scale features of the model wind field are also in close agreement with each other (as well as in qualitative agreement with ERA Interim). At 1200 UTC 24 July, the local-scale feature of the barrier-type jet parallel to the coast are roughly 5 $\mathrm{m} \mathrm{s}^{-1}$ or so stronger than those of ERA Interim, which appears to be partly in response to the models simulating much stronger flow exiting the valley to the east of Mawson. Moreover, the models also simulate another local-scale feature which is the formation of a detached jet to the west of Mawson with speeds of $30-35 \mathrm{~m} \mathrm{~s}^{-1}$. At 0000 UTC $25 \mathrm{July}$, the models show appreciably stronger winds over large swathes of the ocean and ice sheet compared to ERA Interim. Consequently, the model representation of the barrier-type jet shows a larger/broader extent of speed-up as well as sharper gradients at its edges compared to ERA Interim. The models show a strengthening of localised features (not apparent in ERA Interim) such as the detached jet to the west of Mawson, the formation of a detached jet off the Amery Ice Shelf, and a region of strong speed-up (on the landward side of the coast) between Mawson and the Amery Ice Shelf (here the wind speeds reach $35 \mathrm{~m} \mathrm{~s}^{-1}$, i.e. more representative of the peak wind speed measured at Mawson). At 1800 UTC 25 July, the models capture the marked weakening of both the katabatic flow over the land and the geostrophic flow over the ocean, and the consequent cessation of the SWE. 
The broadly similar large-scale near-surface wind field between the three models suggests that a comparison on a more localized scale is required to identify the model differences in wind speed apparent in Fig. 3, and furthermore is suggestive that the general failure of the models to capture the peak wind speed may be due to localized interaction/forcing or simply fundamental problems in the model representation of smaller scale processes. To investigate this, Fig. 5 (a, b, c) shows the 12, 4, and 1.5-km model sea level pressure and $10 \mathrm{~m}$ wind speed at 0000 UTC 25 July (i.e. the time of the peak wind speed) over a $180 \times 180 \mathrm{~km}$ domain. This comparison clearly reveals that both the 4 and $1.5-\mathrm{km}$ models agree in the simulation of a localised region of significant wind enhancement around Mawson during the time of the observed peak wind speed, which is not captured by the 12-km model. Moreover, that in other places the 4 and $1.5-\mathrm{km}$ model representation of the $10 \mathrm{~m}$ wind field and sea level pressure can disagree, sometimes markedly. This is further evident from Fig. 6 (a, b, c) which compares model fields as a function of height of potential temperature and wind speed magnitude for the same time along a transect oriented south-to-north. Here, the 4-km model shows stronger vertical gradients in both of these parameters within 1-2 km of the surface compared to the $1.5-\mathrm{km}$ model.

To investigate whether gravity waves could be influencing the surface wind field at Mawson, Fig. 5 (d, e, f) is analogous to Fig. 5 (a, b, c) but showing the vertical velocity at $500 \mathrm{hPa}$. Here, wave fronts of positive and negative vertical velocity over the land are oriented broadly perpendicularly to the $10 \mathrm{~m}$ wind direction, consistent with the surface wind field forcing gravity waves (e.g., Valkonen et al., 2010). There are clearly differences between the three model simulations, e.g. the wave amplitude increases as the horizontal resolution increases. Moreover, the $1.5-\mathrm{km}$ model shows a series of bands which are indicative of trapped lee waves. Fig. $6(\mathrm{~d}, \mathrm{e}, \mathrm{f})$ is analogous to Fig. $6(\mathrm{a}, \mathrm{b}, \mathrm{c})$ but oriented along a east-to-west 
oriented line transecting Mawson. The models all show the same broad descent of the isentropic surfaces on the leeside of the obstacle immediately to the east of Mawson and associated flow speed-up at near-surface level impinging directly on Mawson, i.e. a so-called downslope windstorm. Note also that the flow shows the existence downstream of a hydraulic jump and trapped lee waves, e.g. see qualitative resemblance to Fig. 4.6 of Durran (1990). There are again clearly differences between the three model simulations, particularly in the enhancement of the lee-slope surface wind and the hydraulic jump (which Durran (1990) suggests are fundamentally linked).

\section{b. Other model sensitivities}

Figure 7 is analogous to Fig. 3 but comparing 4-km model output generated from a number of additional runs examining the sensitivity to choices of model configuration/setup listed in Table I, i.e., relative to the 'base' 4-km model configuration discussed above. Note that the 4-km model sensitivity is examined because this (relative to the $12-\mathrm{km}$ model) showed the largest improvement in the representation of the SWE. A primary aim was to assess whether this was due to either a more realistic representation of the orography or simply due to the improved atmospheric resolution (more explicit/finer representation). This was determined by contrasting the base model run (Run 1) against a run substituted with coarser/smoother orography interpolated from the 12-km model (Run 3). The largest sensitivities were from: i) moving the initialisation time of the model $24 \mathrm{~h}$ earlier which resulted in the temporal evolution of the wind speed being offset by around $6 \mathrm{~h}$ and an increase in surface temperature by a few degrees (Run 2), and ii) replacing the 'sharp' boundary-layer stability function with the 'long tails' function (Run 4), which resulted in appreciably weaker wind speeds and warmer surface temperatures. The 4-km model showed little sensitivity to: i) forcing with 
coarser/smoother orography (Run 3), ii) switching off the fully three-dimensional potential temperature advection scheme and running with the standard 'non-interpolating in the vertical' scheme (Run 5), iii) sea-ice roughness length of $5 \times 10^{-3} \mathrm{~m}$ (Run 6), and iv) running with finer vertical resolution by doubling the number of vertical levels from 70 to 140 (Run 7). Note that an analogous plot to that of Fig. 5 but for Run 3 indicated (not shown) that: i) its representation of gravity waves were qualitatively similar to those of Run 1, but relatively small differences in the magnitude of vertical velocity at $500 \mathrm{hPa}$ existed, and ii) its $10 \mathrm{~m}$ wind field was quantitatively similar to that of Run 1 .

\section{Discussion}

All models capture the qualitative evolution of the SWE which suggests that they are resolving the important forcing mechanisms. A number of reasons suggest that this is dominated by synoptic or large-scale forcing: i) the broader-scale features of the simulations were largely invariant to resolution, ii) all models captured the large pressure drop at Mawson, and iii) the lack of sensitivity to the formulation of the potential temperature advection scheme (Run 6). The large-scale forcing is from the approach of a large depression which results in a strengthening of the horizontal pressure gradient, which prompts a strengthening of the katabatic winds, i.e. by acting in concert with the katabatic pressure gradient force. Furthermore, the low-level cyclonic winds associated with the depression also force a barrier jet along the coastline, such that the interaction/convergence between this 'local' feature and the katabatic flow are important. However, the divergence of the simulated wind speed between the 12 and $4-\mathrm{km}$ models (in contrast to sea level pressure) suggests that the representation of processes and their role on the momentum budget on scales of only a few kilometres are important. 
In particular, the representation of gravity waves is known to be sensitive to horizontal resolution (as was shown here) and to require a high horizontal resolution to capture the wavelength and phase. Interestingly, however, the sensitivity run (Run 3) that forced the 4$\mathrm{km}$ model with coarser orography (from the 12-km model) while maintaining the atmospheric resolution at $4 \mathrm{~km}$ had little impact on the simulated output. This suggests that the main features of the orography are relatively smooth and deficient of small-scale structure, i.e. the improvement in the representation of the SWE by increasing the resolution from $12 \mathrm{~km}$ to 4 $\mathrm{km}$ results from the improved atmospheric resolution, rather than by resolving steeper slopes / stronger asymmetries and consequently the strengthening of non-linear processes associated with gravity waves such as a wind speed-up on the leeward slope.

However, the fact that the results numerically converged to a high-resolution model 'truth' which under-forecast the peak wind speed by around 15\% suggests that the models might be missing or having difficulty representing some fundamental processes (which moreover could be occurring at scales smaller than resolved by the $1.5-\mathrm{km}$ model). The winds at Mawson have an obvious south-easterly signature characteristic of katabatic winds so it is possible that the underestimate is due to a failure in capturing their strengthening. Accurate representation of the turbulent fluxes of katabatic flows (i.e. under very stable conditions) is known to be problematic in models. (An added complication here is that the stability is likely to reduce due to the accompanying warming as the depression approaches Mawson.) Here the 4-km model showed a strong response to changing the form of boundary-layer stability function (c.f. King et al., 2001). Using the 'long-tails' form of stability function (Run 4) resulted in an increase in surface temperature and a decrease in wind speed. Further analysis (not shown) indicated that in addition the temperature aloft reduced by a few degrees, resulting in a 
weakening of the temperature inversion and therefore a weakening of the katabatic pressure gradient force (Parish and Cassano, 2003), i.e. consistent with a weakening of katabatic flow. This is consistent with the 'long-tails' form of stability function resulting in stronger turbulent mixing (i.e. the 'sharp' ('long-tails') function decays rapidly (slowly) with increasing stability) of warmer air at higher levels within the temperature inversion down to the ground. Another difficulty in the representation of katabatic winds is that high vertical resolution is required at the near-surface to capture the strong vertical gradients associated with the low-level jet feature and the strong inversion which characterise it. However, running with a finer vertical resolution (Run 7) did not influence the 4-km model output at Mawson (although it did affect the $10 \mathrm{~m}$ wind (generally a speeding up) elsewhere), suggesting that the base model vertical resolution is sufficient to resolve the inversion and katabatic winds in the vicinity of Mawson. Furthermore, the modelled inversion strength would be dependent on the correct representation of cloud cover, however, this has not been validated in this region.

It should be noted that a point-wise comparison between the model and observations could be inappropriate, and that the results simply reflect the difficulty validating high-resolution NWP simulations in data sparse regions and regions characterised by strong gradients in wind. For example: the i) 4 and $1.5-\mathrm{km}$ model representation of wind speed agrees in some places, such as around Mawson, but disagree elsewhere, and ii) the model winds peaked slightly to the west with values more representative of the peak wind speed measured at Mawson. It is further possible that the bias reflects errors in the reanalysis used for the initial conditions (e.g., Bromwich et al., 2003) or synoptic-scale forecast errors in the fields produced by the global MetUM which were used here for boundary conditions. 
Finally, the model simulations revealed the formation of two detached jets to the west and east of Mawson, resulting in winds speeds in excess of $35 \mathrm{~m} \mathrm{~s}^{-1}$. Another interesting feature is the strong speed-up as the katabatic flow approaches the coast to the east of Mawson. Investigation of the topographic gradient at this location showed that the terrain did not steepen (not shown), suggesting that the acceleration of the katabatic winds across the coastline by the synoptic pressure gradient could be leading to the formation of localised wind jets parallel to the coastline (e.g. Hunt et al., 2004; Orr et al., 2005a).

\section{Summary}

SWEs are a characteristic feature during winter around the coast of Antarctica, particularly around East Antarctica. The primary aim of this study was to investigate the sensitivity of the MetUM simulation of a SWE to horizontal resolution, i.e. any differences due to the improved orography and/or improved representation of the dynamical and physical processes associated with Antarctica and SWEs at higher horizontal resolution. The ability of models to simulate such events is challenging as a number of components are required to be captured. The secondary aim of this study was to investigate the forcing mechanisms and meteorological understanding of SWEs, and in particular to determine the relative impact of topographic influences and synoptic forcing and their interaction.

All the model simulations capture the general qualitative evolution of the SWE, suggesting that: i) its forcing mechanism is dominated by synoptic-scale forcing, and ii) the MetUM would have provided useful qualitative guidance if used to forecast such events. However, the simulated wind speed strengthened strongly (weakly) between the 12 and 4-km (4 and 1.5-km) model simulations, suggesting that they are numerically converging to a high- 
resolution model 'truth' which under-forecast the peak wind speed by around $15 \%$. Further high resolution studies are required to determine the representativeness of these results and whether the MetUM had a systematic tendency to underestimate the wind speed of such extreme events. However, this finding is consistent with other studies using the MetUM (Webster et al., 2008) and WRF (Powers 2007), and suggests that the models might be missing or having difficulty representing some fundamental processes, such as fine scale gravity waves or turbulent mixing under stable conditions.

Previous studies had hypothesised that SWEs result from the enhancement of strong katabatic flow by a strengthening of the pressure gradient force associated with the approach of a deep depression toward the coast. However, in the case study analysed here the approach of the depression additionally resulted in a barrier jet and a detached jet, as well as a strengthening of the katabatic flow, suggesting a strong topographic influence on the forcing mechanism (e.g. Nigro et al., 2012). This resulted in a region of strong convergence at the coastline and considerable interaction between the various components.

\section{Acknowledgements}

The authors are grateful to the two anonymous reviewers, whose detailed comments greatly improved the paper. The authors appreciate the support of the University of WisconsinMadison Antarctic Meteorological Research Center for the data set, data display, \& information, NSF grant number ANT-0838834. The authors particularly want to thank NCAS Computational Modelling Services for much support running the MetUM, as well as thank Steve Colwell, Julian Hunt, John King, Ian Renfrew, and Alexandra Weiss for useful conversations. 


\section{References}

Adams N. 2005. Identifying the characteristics of strong southerly wind events at Casey Station in East Antarctica using a numerical weather prediction system. Monthly Weather Review 113: 3548 - 3561. DOI: 10.1175/MWR3050.1.

Bracegirdle TJ. 2012. Climatology and recent increase of westerly winds over the Amundsen Sea derived from six reanalyses. International Journal of Climatology 33, $843-851$. DOI: $10.1002 /$ joc. 3473 .

Bracegirdle TJ, Marshall GJ. 2012. The reliability of Antarctic tropospheric pressure and temperature in the latest global reanalyses. Journal of Climate 25: 7138 - 7146. DOI: 10.1175/JCLI-D-11-00685.1.

Bromwich DH, Monaghan AJ, Powers JG, Cassano JJ, Wei H, Kuo Y, Pellegrini A. 2003. Antarctic Mesoscale Prediction System (AMPS): A case study from the 2000-01 field season. Monthly Weather Review 131, 412-434. DOI: 10.1175/15200493(2003)131<0412:AMPSAA>2.0CO;2.

Bromwich DH, Morgan AJ, Manning KW, Powers JG. 2005. Real-time forecasting for the Antarctic: An evaluation of the Antarctic Mesoscale Prediction System (AMPS). Monthly Weather Review 133, 579-603. DOI: 10.1175/MWR-2881.1. 
Bromwich DH, Hines KM, Bai LS. 2009. Development and testing of polar weather research and forecasting model: 2. Arctic Ocean. Journal of Geophysical Research 114: D08122. DOI: 10.1029/2008JD010300.

Brown AR, Beare RJ, Edwards JM, Lock AP, Keogh SJ, Milton SF, Walters DN. 2008. Upgrades to the boundary-layer scheme in the Met Office numerical weather prediction model. Boundary Layer Meteorology 128: 117 - 132. DOI: 10.1007/s10546-008-9275-0.

Comiso JC. 1999. Bootstrap sea ice concentrations from NIMBUS-7 SMMR and DMSP SMM/I. http://nsidc.org/data/nsidc-0079.html. National Snow and Ice Data Center, Boulder, Colorado.

Davies T, Cullen MJP, Malcolm AJ, Mawson MH, Stainforth A, White AA, Wood N. 2005. A new dynamical core for the Met Office's global and regional modelling of the atmosphere. Quarterly Journal of the Royal Meteorological Society 131: 1759 - 1782. DOI: $10.1256 /$ qj.04.101.

Durran DR. 1990. Mountain waves and downslope winds. Atmospheric Processes over Complex Terrain, Meteorological Monographs No. 45. American Meteorological Society: Boston; pp $59-81$.

Dee DP, and co-authors. 2011. The ERA-Interim reanalysis: configuration and performance of the data assimilation system. Quarterly Journal of the Royal Meteorological Society 137: 553 - 597. DOI: 10.1002/qj.828. 
Gallee H, Pettre P, Schayes G. 1996. Sudden cessation of katabatic winds in Adelie Land, Antarctica. Journal of Applied Meteorology 35: 1142 - 1152. DOI: 10.1175/15200450(1996)035<1142:SCOKWI >2.0.CO;2.

Heinemann G. 1997. Idealized simulations of the Antarctic katabatic wind system in a threedimensional mesoscale model. Journal of Geophysical Research 102: 13825 - 13834. DOI: $10.1029 / 97 J D 00457$.

Hunt JCR, Orr A, Rottman JW, Capon R. 2004. Coriolis effects in mesoscale flows with sharp changes in surface conditions. Quarterly Journal of Royal Meteorological Society 130: 2703 - 2731. DOI: 10.1256/qj.04.14.

King JC, Connolley WM. 1997. Validation of the surface energy balance over the Antarctic ice sheet in the U.K. Meteorological Office Unified Climate Model. Journal of $\begin{array}{lllllll}\text { Climate } & 10: & 1273 & - & 1287 . & \text { DOI: } & 10.1175 / 1520-\end{array}$ 0442(1997)010<1273:VOTSEB>2.0.CO;2.

King JC, Turner J. 1997. Antarctic Meteorology and Climatology. Cambridge University Press: Cambridge, U.K.; pp 425. DOI: 10.1017/CBO9780511524967.

King JC, Connolley WM, Derbyshire SH. 2001. Sensitivity of modelled Antarctic climate to surface and boundary-layer flux parametrizations. Quarterly Journal of Royal Meteorological Society 127: 779 - 794. DOI: 10.1002/qj.49712757304. 
Liu H, Jezek K, Li B, Zhao Z. 2001. Radarsat Antarctic Mapping Project digital elevation model version 2. Boulder, Colorado: National Snow and Ice Data Center. Digital media.

Nigro MA, Cassano JJ, Lazzara MA, Keller LM. 2012. Case study of a barrier wind corner jet off the coast of the Prince Olav Mountains, Antarctica. Monthly Weather Review 140: 2044-2063. DOI: 10.1175/MWR-D-11-00261.1.

O’Connor WP, Bromwich DH, Carrasco JF. 1994. Cyclonically forced barrier winds along the Transantarctic Mountains near Ross Island. Monthly Weather Review 122: 137150. DOI: 10.1175/1520-0493(1994)122<0137:CFBWAT>2.0.CO;2.

Orr A, Cresswell D, Marshall GJ, Hunt JCR, Sommeria J, Wang CG, Light M. 2004. A 'lowlevel' explanation for the recent large warming trend over the western Antarctic Peninsula involving blocked winds and changes in zonal circulation. Geophysical Research Letters 31: L06204. DOI: 10.1029/2003GLO19160.

Orr A, Hunt JCR, Capon R, Sommeria J, Cresswell D, Owinoh D. 2005a. Coriolis effects on wind jets and cloudiness along coasts. Weather 60: 291 - 299. DOI: 10.1256/wea.219.04.

Orr A, Hanna E, Hunt JCR, Cappelen J, Steffen K, Stephens A. 2005b. Characteristics of stable flows over Southern Greenland. Special edition of Pure and Applied Geophysics on 'Weather and Climate'. DOI: 10.1007/s00024-005-2691-x. 
Orr A, Marshall GJ, Hunt JCR, Sommeria J, Wang CG, Lipzig NV, King JC. 2008. Characteristics of summer airflow over the Antarctic Peninsula in response to recent strengthening of westerly winds. Journal of the Atmospheric Sciences 65: 1396 1413. DOI: $10.1175 / 2007 J A S 2498.1$.

Owinoh A, Hunt JCR, Orr A, Clark P, Klein R, Fernando HJS, Nieuwstadt FTN. 2005. Effects of changing surface heat flux on the atmospheric boundary layer over flat terrain. Boundary Layer Meteorology 116: 331 - 361. DOI: 10.1007/s10546-0042819-z.

Parish TR. 1988. Surface winds over the Antarctic continent: a review. Reviews of Geophysics 26: 169-180. DOI: 10.1029/RG026i001p00169.

Parish TR, Bromwich DH. 1987. The surface windfield over the Antarctic ice sheets. Nature 328: 51 - 54. DOI: 10.1038/328051a0.

Parish TR, Bromwich DH. 1998. A case study of Antarctic katabatic wind interaction with large-scale forcing. Monthly Weather Review 126: 199-209. DOI: 10.1175/15200493(1998)126<0199:ACSOAK>2.0.CO;2.

Parish TR, Cassano JJ. 2003. The role of katabatic winds on the Antarctic surface wind regime. Monthly Weather Review 131: 317 - 333. DOI: 10.1175/15200493(2003)131<0317:TROKWO>2.0.CO;2. 
Petersen GN, Renfrew IA, Moore GWK. 2009. An overview of barrier winds off southeastern Greenland during the Greenland Flow Distortion experiment. Quarterly Journal of the Royal Meteorological Society 135: 1950 - 1967. DOI: 10.1002/qj.455.

Petrelli P, Bindoff NL, Bergamasco A. 2008. The sea ice dynamics of Terra Nova Bay and Ross Ice Shelf polynyas during spring and winter simulation. Journal of Geophysical Research 113: DOI: 10.1029/2006JC004048.

Powers JG. 2007. Numerical prediction of an Antarctic severe wind event with the Weather Research and Forecasting (WRF) model. Monthly Weather Review 135: 3134-3157. DOI: $10.1175 / \mathrm{MWR} 3459.1$.

Rees JM, Denholm-Price JCW, King JC, Anderson PS. 2000. A climatological study of internal gravity waves in the atmospheric boundary layer overlying the Brunt Ice Shelf, Antarctica. Journal of the Atmospheric Sciences 57: 511-526. DOI: 10.1175/1520-0469(2000)057<0511:ACSOIG>2.0.CO;2.

Renfrew, IA, Anderson PS. 2006. Profiles of katabatic flow in summer and winter over Coats Land, Antarctica. Quarterly Journal of the Royal Meteorological Society 132: 779802. DOI: $10.1256 /$ qj.05.148.

Reynolds RW, Smith TM, Liu C, Chelton DB, Casey KS, Schlax MG. 2007. Daily highresolution-blended analyses for sea surface temperature. Journal of Climate 20: 5473 - 5496. DOI: 10.1175/2007JCLI1824.1. 
Smith SD. 1988. Coefficients for sea surface wind stress, heat flux and wind profiles as a function of wind speed and temperature. Journal of Geophysical Research 93: 1546715472. DOI: $10.1029 / \mathrm{JC} 093 \mathrm{iC} 12 \mathrm{p} 15467$.

Streten NA. 1968. Some characteristics of strong wind periods in coastal East Antarctica. Journal of Applied Meteorology 7: 46 - 52. DOI: 10.1175/15200450(1968)<007:SCOSWP>2.0.CO;2.

Streten NA. 1990. A review of the climate of Mawson - a representative strong wind site in East Antarctica. Antarctic Science 2: 79 - 89. DOI: 10.1017/S0954102090000098.

Tastula EM, Vihma T. 2011. WRF model experiments on the Antarctic atmosphere in winter. Monthly Weather Review 139: DOI: 10.1175/2010MWR3478.1, 1279 - 1291.

Turner J, Tom AL-C, Marshall GJ, Pendlebury S, Adams N. 2001. An extreme wind event at Casey Station, Antarctica. Journal of Geophysical Research 106: 7291-7311. DOI: 10.1029/2000JD900544.

Turner J, Chenoli SN, Samah A, Marshall GJ, Phillips T, Orr A. 2009. Strong wind events in the Antarctic. Journal of Geophysical Research 114: D18103. DOI: 10.1029/2008JD011642.

Valkonen T, Vihma T, Kirkwood S, Johansson MM. 2010. Fine-scale model simulation of gravity waves generated by Basen nunatak in Antarctica. Tellus A 62: 319-332. 
van den Broeke MR, van Lipzig NPM. 2003. Factors controlling the near-surface wind field in Antarctica. Monthly Weather Review 131: 733-743. DOI: 10.1111/j.16000870.2010.00443.x.

Wamser C, Martinson DG. 1993. Drag coefficients for winter Antarctic pack ice. Journal of Geophysical Research 98: 12431 - 12437. DOI: 10.1029/93JC00655.

Watanabe S, Sato K, Takahashi M. 2006. A general circulation model study of the orographic gravity waves over Antarctica excited by katabatic winds. Journal of Geophysical Research 111: D18104. DOI: 10.1029/2005JD006851.

Webster S, Brown AR, Cameron DR, Jones CP. 2003. Improvements to the representation of orography in the Met Office Unified Model. Quarterly Journal of the Royal Meteorological Society 129: 1989 - 2010. DOI: 10.1256/qj.02.133.

Webster S, Uddstrom M, Oliver H, Vosper S. 2008. A high-resolution modelling case study of a severe weather event over New Zealand. Atmospheric Science Letters 9: 119 128. DOI: $10.1002 /$ asl.172.

Weiss, AI, King J, Lachlan-Cope T, Ladkin R. 2011. On the effective aerodynamic and scalar roughness length of Weddell Sea ice. Journal of Geophysical Research 116: D19119. DOI: $10.1029 / 2011 J D 015949$. 
Wood N, and Mason P. 1993. The pressure force induced by neutral, turbulent flow over hills. Quarterly Journal of the Royal Meteorological Society 119: 1233-1267. DOI: 10.1002/qj.49711951402.

Label Description

Run $1 \quad$ Base 4-km model

Run 2 Base 4-km model + beginning the suite of model runs from an initialisation time $24 \mathrm{~h}$ earlier (0000 UTC 23 July) and running out to $+72 \mathrm{~h}$.

Run 3

Base 4-km model + orography interpolated from the 12-km model orography of Antarctica.

Run $4 \quad$ Base 4-km model + Long tails scheme

Run 5 Base 4-km model +replacing the 3d advection scheme with the standard 'non interpolating in the vertical' scheme

Run 6

Base 4-km model + sea-ice roughness length of $5 \times 10^{-3} \mathrm{~m}$ Run 7

Base 4-km model + 140 vertical levels

Table I: List of additional 4-km model sensitivity runs (referred to as Runs 2 to 7), starting from the 'base' 4-km model (referred to as Run 1). 


\section{List of figure captions}

Figure 1: Map of Antarctica showing the location of Mawson (represented by filled black circle) and the 12, 4, and $1.5 \mathrm{~km}$ grids used in the nested UM simulations (solid black line). Also shown are: i) the terrain elevation (m) used by ERA Interim (shading), ii) the domain size of the $1800 \times 1800 \mathrm{~km}$ panels of Fig. 4 (long dashed line), and iii) the sea ice edge (defined as $15 \%$ concentration) on 0000 UTC 25 July 2004 (solid grey line).

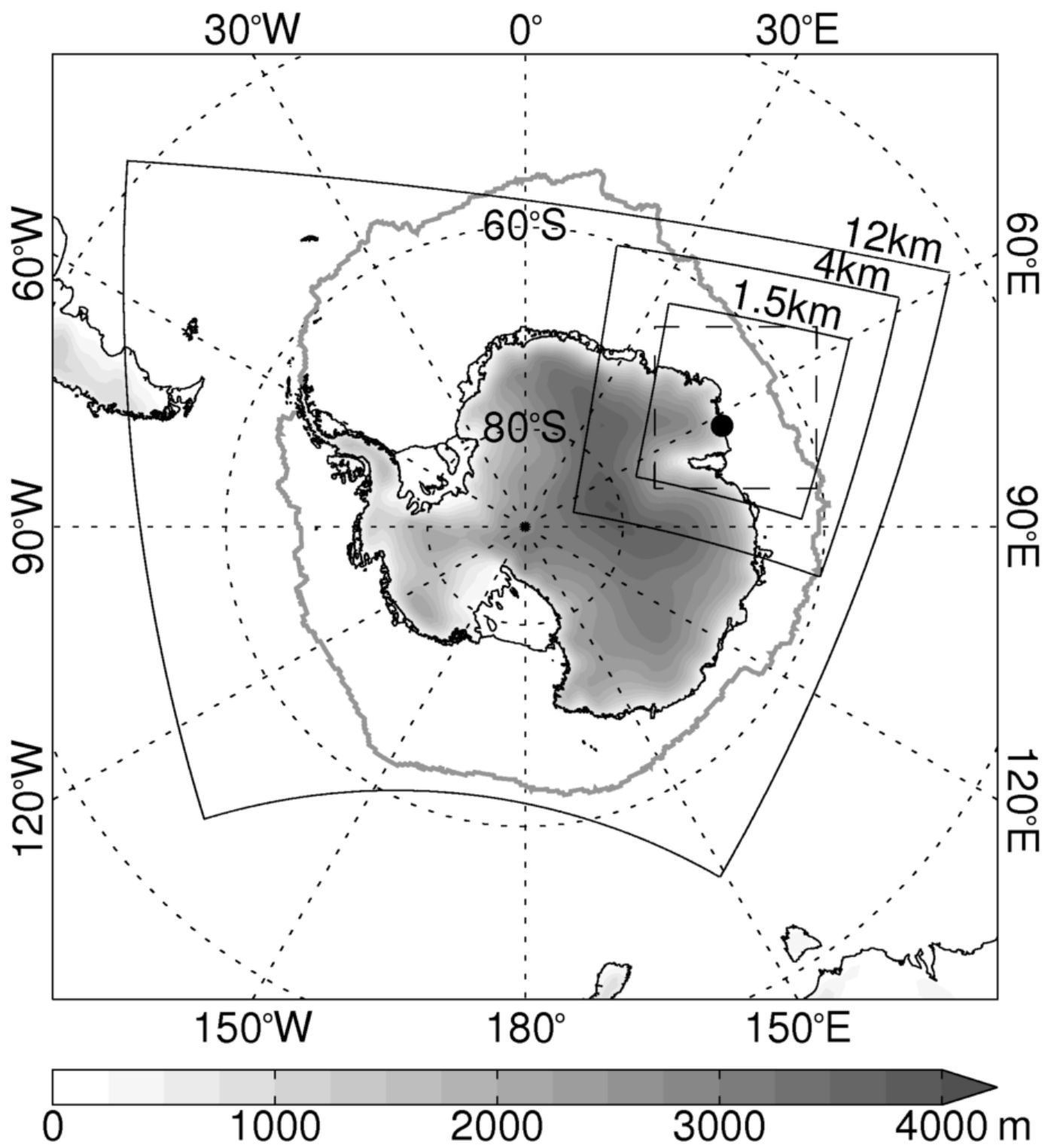


Figure 2: Comparison of orography height $(\mathrm{m})$ along transects intersecting Mawson (represented by the filled back circle) oriented in the a) south-to-north and b) west-to-east directions between the DEM, ERA Interim, and the 12, 4 and 1.5-km grids. In panel a (panel b) south (west) of Mawson is on the left hand side. 
(a)
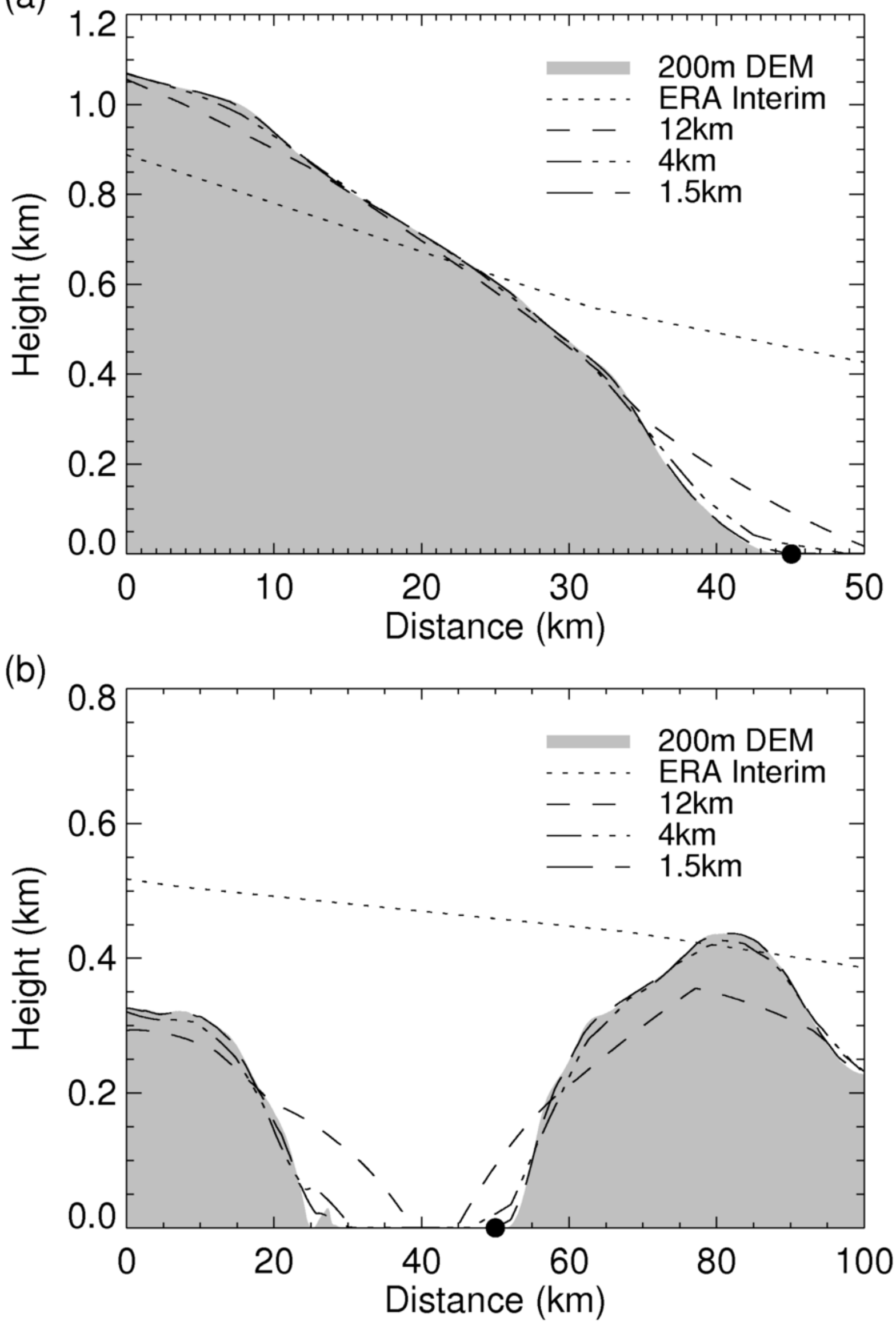

This article is protected by copyright. All rights reserved. 
Figure 3: Comparison of observations and the 12, 4 and 1.5- $\mathrm{km}$ model simulations at 3hourly intervals at Mawson station for a) sea level pressure (units of $\mathrm{hPa}$ ), b) $2 \mathrm{~m}$ temperature (units of ${ }^{\circ} \mathrm{C}$ ), c) $10 \mathrm{~m}$ wind speed (units of $\mathrm{m} \mathrm{s}^{-1}$ ), and d) $10 \mathrm{~m}$ wind direction (units of ${ }^{\circ}$ ) spanning the duration of the SWE. Also shown are the 6-hourly values from ERA Interim. The time axis shows both the actual time and the simulation/forecast time.
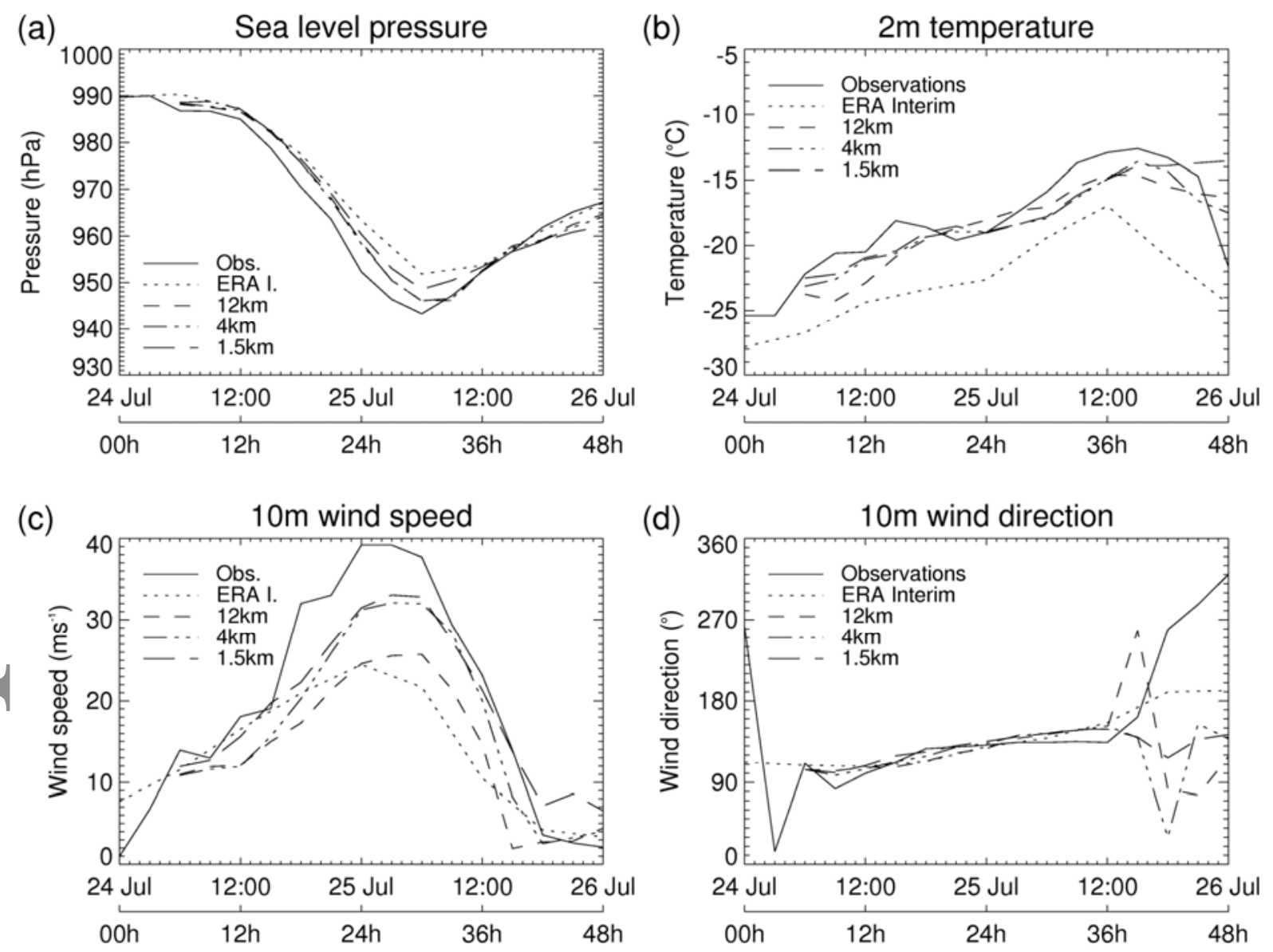

This article is protected by copyright. All rights reserved. 
Figure 4: Comparison of sea level pressure (contours with interval of $4 \mathrm{hPa}$ over the sea, not included over land) and $10 \mathrm{~m}$ wind field (reference vector shown for $30 \mathrm{~m} \mathrm{~s}^{-1}$ ) and its magnitude (shaded colours with interval of $2.5 \mathrm{~m} \mathrm{~s}^{-1}$ ) between ERA Interim (a-c; row 1) and the UM simulations (12-km grid (d-f; row 2), 4-km grid (g-i; row 3), 1.5-km grid (j-l; row 4)) at 1200 UTC 24 July 2004 (column 1), 0000 UTC 25 July 2004 (column 2), and 1800 UTC 25 July 2004 (column 3). The location of Mawson is indicated by the filled white circle. The domain size of each panel is $1800 \times 1800 \mathrm{~km}$. All results are remapped to the 4-km grid using bilinear interpolation. For clarity not every wind vector is shown. 
Figure 5: 12-km (column 1), 4-km (column 2) and 1.5-km (column 3) model fields at the time of the peak wind occurrence at 0000 UTC 25 July 2004. First row is as Fig. 4 (i.e. panels e, $\mathrm{h}, \mathrm{k})$ but for a zoomed in $(180 \times 180 \mathrm{~km})$ region over Mawson (indicated by the filled white circle). Second row is as first row but shows vertical velocity at $500 \mathrm{hPa}$ (shaded colours with interval of $0.05 \mathrm{~m} \mathrm{~s}^{-1}$ ) and $10 \mathrm{~m}$ winds (reference vector shown for $30 \mathrm{~m} \mathrm{~s}^{-1}$ ). Note that the $10 \mathrm{~m}$ wind magnitude in the first row has an interval of $1 \mathrm{~m} \mathrm{~s}^{-1}$ (shaded colours). All results are remapped to the $4-\mathrm{km}$ grid using bilinear interpolation. For clarity not every wind vector is shown.

(a)

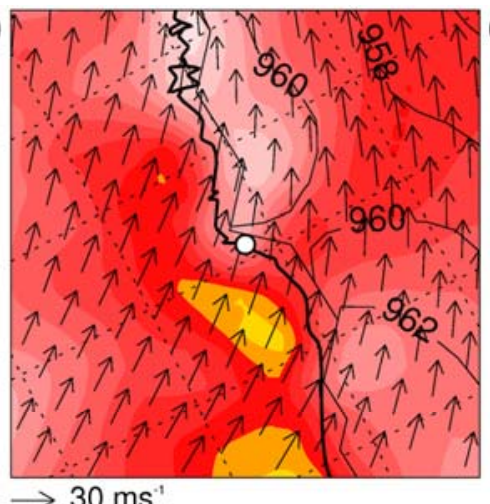

$\rightarrow 30 \mathrm{~ms}^{-1}$ (b)

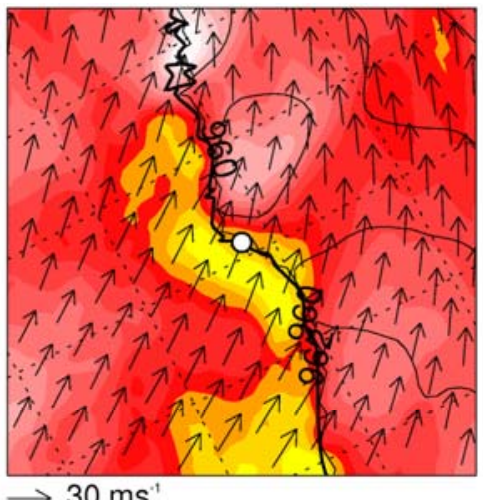

(c)

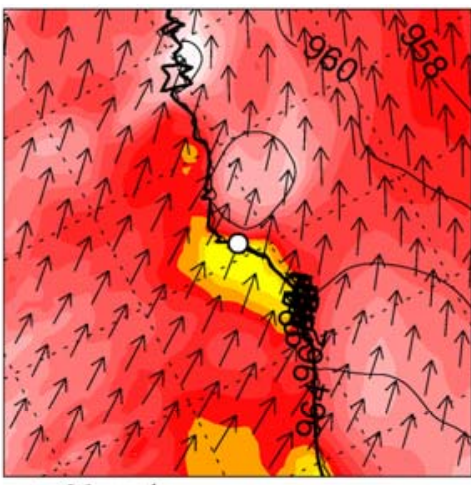

$\rightarrow 30 \mathrm{~ms}$

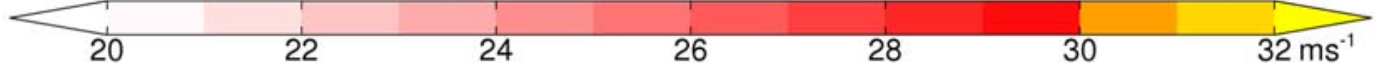

(d)
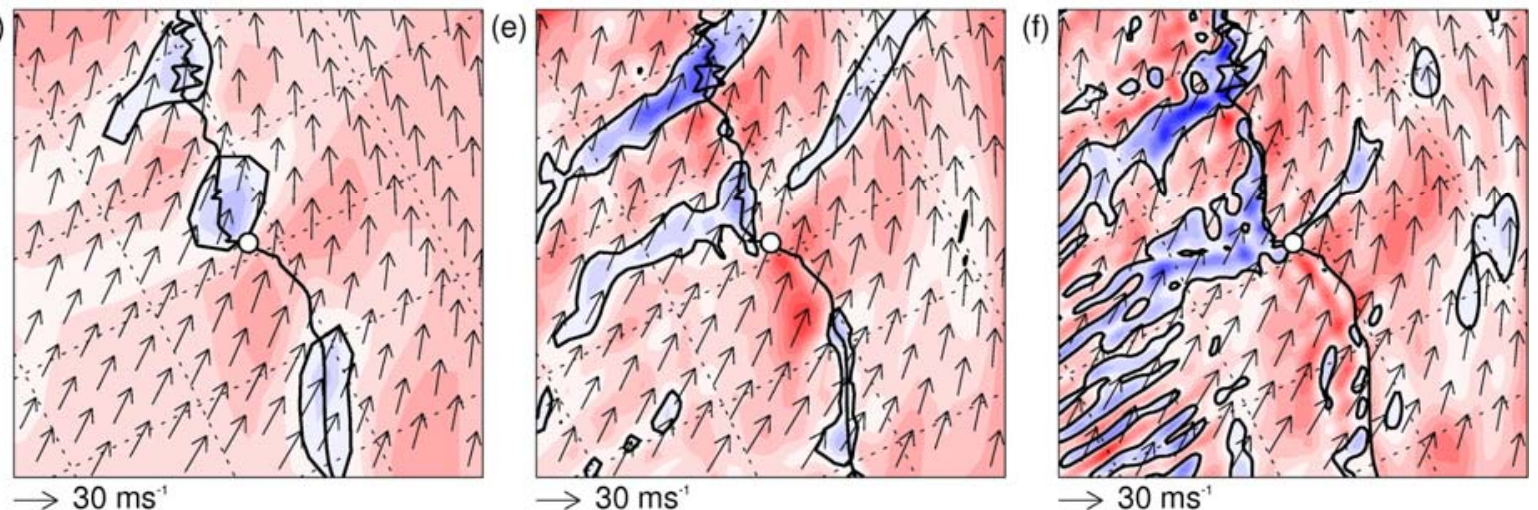

$\rightarrow 30 \mathrm{~ms}^{-1}$

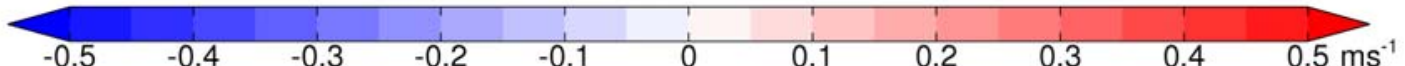

This article is protected by copyright. All rights reserved. 
Figure 6: 12-km (column 1), 4-km (column 2) and 1.5-km (column 3) model fields of potential temperature (contours with interval of $5 \mathrm{~K}$ ) and horizontal wind speed (shaded colours with interval of $2.5 \mathrm{~m} \mathrm{~s}^{-1}$ ) at the time of the peak wind occurrence at 0000 UTC 25 July 2004. First row shows height $(\mathrm{km})$ - latitude $\left({ }^{\circ}\right)$ cross-sections along a south-north oriented line transecting Mawson (represented by the filled white circle). Second row shows height $(\mathrm{km})$ - longitude $\left(^{\circ}\right)$ cross-sections along a west-east oriented line transecting Mawson.

(a)

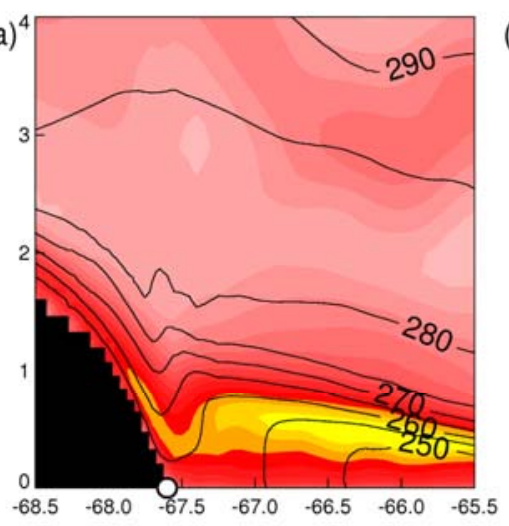

(d)

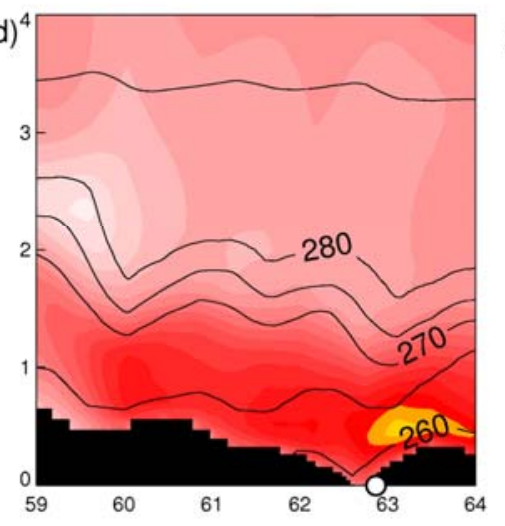

$(b)^{4}$

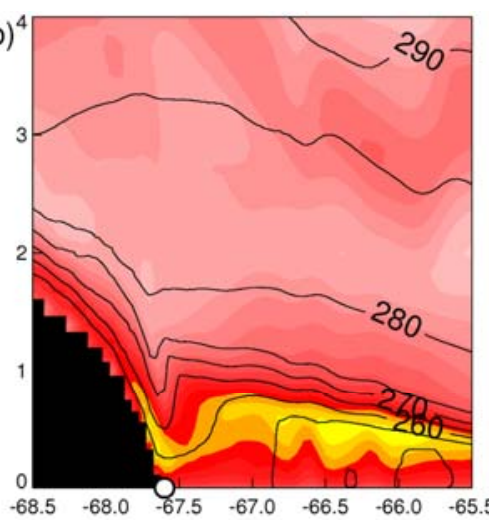

(c)

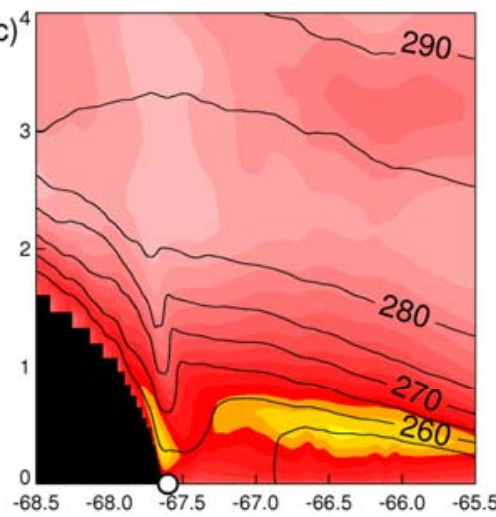

$(e)^{4}$

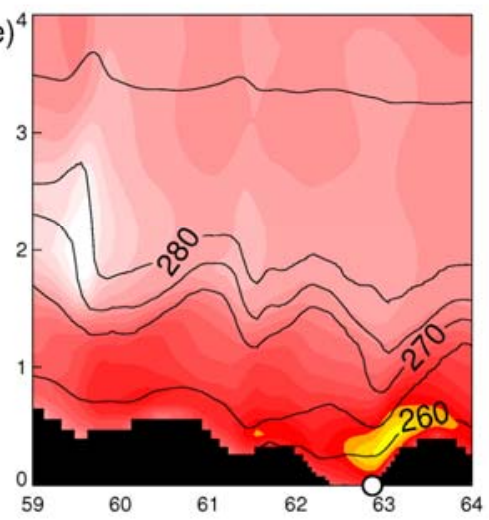

$(\mathrm{f})^{4}$

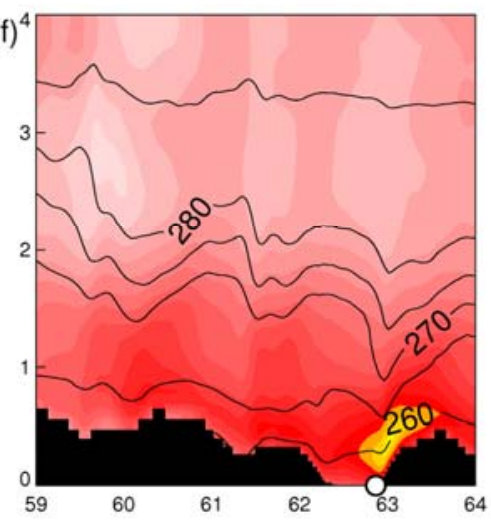

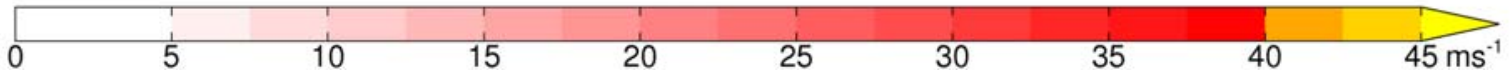

This article is protected by copyright. All rights reserved. 
Figure 7: As Fig. 3 but comparing the base 4-km model to a series of sensitivity experiments described in Table 1 in which the horizontal resolution is kept at $4 \mathrm{~km}$ but the model configuration/setup including dynamics and physics choices are varied.
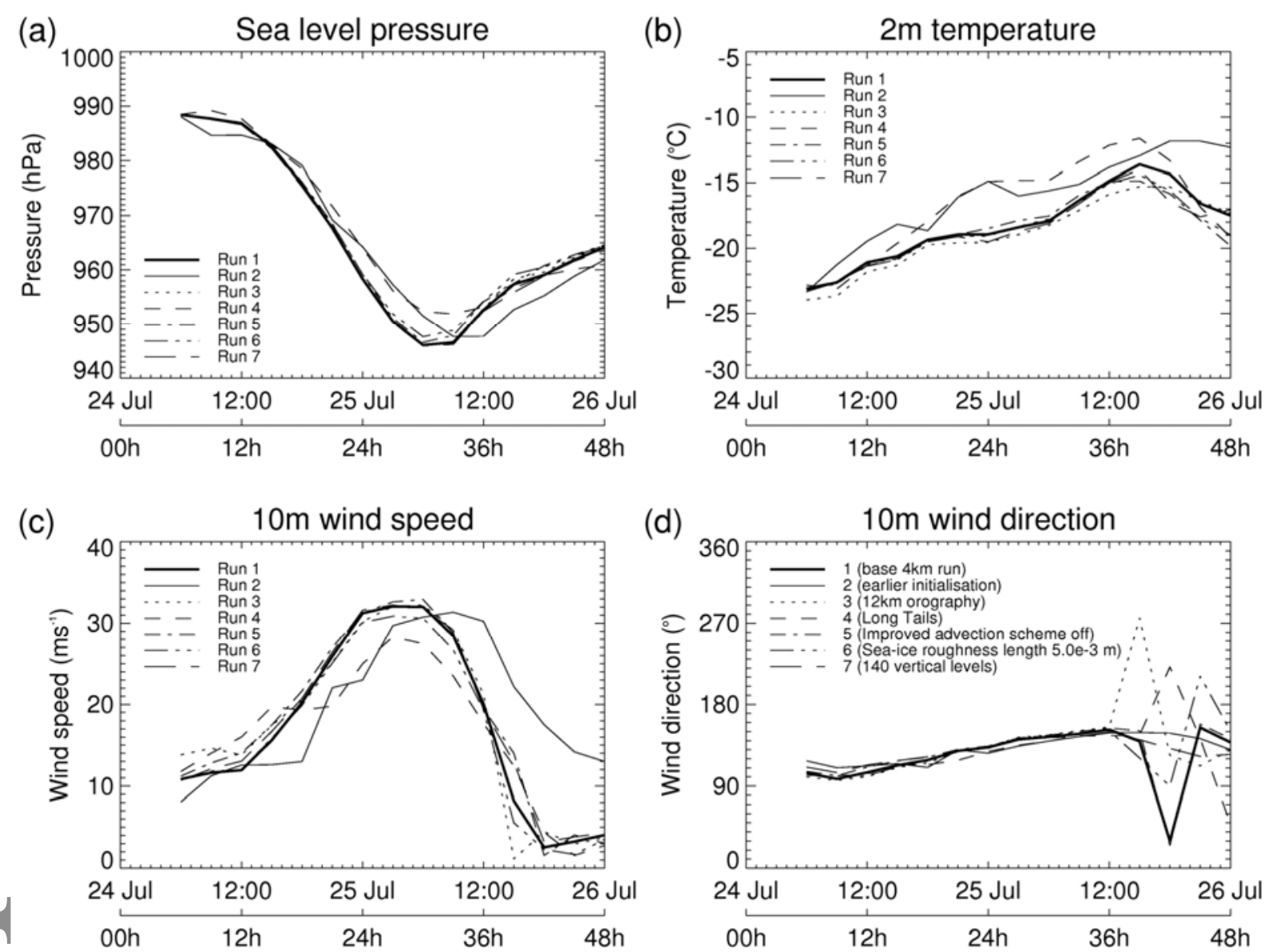

This article is protected by copyright. All rights reserved. 